\title{
QUESTÕES DE GÊNERO NA ESCOLA: PERSPECTIVA DE ALUNXS DA EDUCAÇÃO INFANTIL SOBRE PADRÕES ESTABELECIDOS SOCIALMENTE
}

\author{
Fernanda Marques da Silva ${ }^{1}$ \\ Elenise da Silva Pereira² \\ Ben Hur Graboski Pinheiro ${ }^{3}$ \\ Eliane Fraga da Silveira ${ }^{4}$
}

Resumo: Os bolsistas do PIBID/Ulbra desenvolveram atividades com o objetivo de dissociar a percepção dos alunxs sobre hábitos ditos de menino e menina, por meio da discussão de temas relacionados a gênero na infância. $O$ estudo foi desenvolvido em uma escola pública com turmas da Educação Infantil, onde foram realizadas cinco atividades. Os resultados apontaram que as crianças conhecem os padrões estabelecidos socialmente, mas se mostram contrários a eles, afirmando que cada individuo possui sua liberdade de expressão. Percebe-se que práticas diferenciadas são fundamentais no processo de aprendizagem, propiciando a abordagem de assuntos relacionados a gênero de forma interessante e natural.

Palavras-Chave: Educação; Gênero; Padrões Sociais.

Abstract: The PIBID/Ulbra fellows developed activities with the objective of to
dissociate students' perceptions about the habits of boys and girls, through the
discussion of gender issues in childhood.The study was developed in a public school
with classes in Early Childhood Education, where five activities were carried out.
The results pointed out that the children know the socially established patterns, but
they are contrary to them, affirming that each individual possesses their freedom
of expression. It is noticed that differentiated practices are fundamental in the
learning process, providing an interesting and natural approach to gender issues. Keywords: Education; Gender; Social Standards.

\section{Introdução: A construção dos gêneros}

O conceito de gênero foi elaborado por feministas anglo-saxãs no início da

\footnotetext{
1 Graduada em Ciências Biológicas pela Universidade Luterana do Brasil. E-mail: fmarquesO28@gmail.com.

2 Mestranda do Programa de Pós-Graduação em Ensino de Ciências e Matemática da Universidade Luterana do Brasil. E-mail: elenise.spg@hotmail.com.

3 Graduando do curso de Ciências Biológicas da Universidade Luterana do Brasil. E-mail: benhurgraboski@gmail. com. 
década de 70 e estas criticavam o caráter social de distinção baseada no sexo. O movimento lutava pela rejeição do determinismo biológico que estava presente em termos como diferença sexual, as feministas buscavam explicar que a feminilidade e a masculinidade não são exclusivamente características biológicas. Conforme Meyer (2003, p.16):

conceito de gênero passa a englobar todas as formas de construção social, cultural e linguística implicadas com os processos que diferenciam mulheres de homens incluindo aqueles processos que produzem seus corpos, distinguindo-os e separando-os como corpos dotados de sexo, gênero e sexualidade.

Quando o gênero é considerado uma construção social, compreende-se de que há muitas formas de se definir a masculinidade e a feminilidade, porém a sociedade considera apenas uma forma correta, ou seja, uma maneira de ser homem e uma maneira de ser mulher. Então é definido um padrão a ser seguido e aqueles que não seguem tal padrão são ditos anormais (MARTINS, 2017).

Os padrões culturais de gênero e sexualidade são construídos historicamente e reproduzidos em diversos âmbitos sociais, como a família, igreja e a escola (MARTINS, 2017). Essas instituições influenciam diretamente no desenvolvimento e aprendizagem dos indivíduos, por serem exemplos em questões de comportamentos que são considerados adequados e normais. $O$ indivíduo que está em processo de formação, em sua infância e juventude, que não se ajusta a esta normativa, passa então a ser alvo de abjeções nos diversos lugares que frequenta.

A prática educacional é influenciada principalmente pela esfera familiar, e os familiares impõem nos indivíduos maneiras que consideram corretas de agir. Furlani (2005, p. 51) explica que:

Pais, mães e todos/as que se relacionam com a criança ou jovem, apresentam um
comportamento que reforça (ou que constrói) as características sociais esperadas
para aquele sexo/gênero. Trata-se de todo um conjunto de aspectos diversos como
atitudes, linguagem, vestimentas, brinquedos, que, uma vez expressados no com-
portamento dos adultos, familiares e da sociedade, de um modo geral, contribuirão
para a definição de uma identidade subjetiva a ser incorporada por aquela pessoa.

Sobre tais padrões Martins (2017) diz que estes impõem nos indivíduos certo caráter patológico a tudo que não os correspondem, e assim estimulam a discriminação e o preconceito. Tais práticas estão impregnadas na sociedade e são muito frequentes no dia a dia escolar. Atividades que desenvolvam inclusão às diver- 
sidades sexuais e de gênero na escola ainda são polêmicas e muitas vezes proibidas neste ambiente. São comuns situações em que os estudantes são alvos de gozação e piada, simplesmente por apresentarem comportamentos que pela sociedade não são esperados ou adequados. Esses comportamentos podem ser referentes à sua orientação sexual, seu jeito, sua maneira de se vestir, de viver, etc.

Com isso, os bolsistas do Programa Institucional de Bolsas de Iniciação à Docência do curso de Ciências Biológicas (PIBID/Ulbra), desenvolveram atividades com o objetivo de desconstruir estereótipos ditados pelo determinismo biológico e cultural, promovendo a discussão de temas relacionados a gênero na infância, se utilizando de métodos que demonstrassem de maneira lúdica e visual o valor existente na diversidade. Para tanto, foram levantados assuntos que envolveram preferências, como cor preferida, brinquedos, vestimentas, e $\circ$ ato de brincar propriamente dito.

\section{Trabalhando com crianças}

Ao realizar um trabalho que trata destes temas com crianças é preciso estar atento ao tipo de metodologia que será empregada. Eugenio (2016, p. 143) explica que "é necessário que se desvincule totalmente da ideia de que a criança é um adulto em miniatura, e a compreenda como um ser com características próprias, que possui suas ideias e interesses de forma diferente dos adultos". É preciso se atentar também aos meios em que estes sujeitos estão inseridos, principalmente ao seu contexto social, pois muitas vezes isso pode explicar seus comportamentos e ações.

As crianças geralmente não expressam seus preconceitos, ideais e vivências através de conversas, mas utilizando a metodologia correta é possivel estimulá-las para que possam expressar suas opiniões (EUGENIO, 2016). Bem como, inúmeros estudos apontam que crianças contribuem de forma ativa na produção e mudança cultural, assim compreende-se que a cultura não é somente internalizada pelas crianças, mas pode ser modificada pela inserção delas em um contexto estabelecido pelas suas interações (NOVAKOWSKI, COSTA e MARCELLO, 2016).

Segundo Corsaro (2009, p. 31), as crianças "aprendem criativamente informações do mundo adulto para produzir suas culturas próprias e singulares". As crianças são grandes observadoras da vida adulta, e através dessas análises se espelham em atitudes que posteriormente serão reproduzidas nos ambientes que frequentam. No dia a dia escolar é possível observar que as crianças delimitam espaços e que brincam de brincadeiras de acordo com o gênero de cada uma, colocando barreiras que separam meninos de meninas, e quando um destes quer participar da brincadeira dita do gênero do outro, acaba se sentindo desconfortável e é discriminado pelos demais. De acordo com Novakowski, Costa e Marcello (2016), estas diferenças manifestadas por essas crianças são o resultado da cultura em que estão inseridas, pois acabam reproduzindo o que captam dos diálo- 
gos adultos. Há inúmeras agências que regulam a conduta dos indivíduos como escolas, igrejas, mídia e a própria familia, onde ditam às crianças maneiras de ser de acordo com os parâmetros criados e estabelecidos socialmente.

As autoras ainda explicam que a família insere a criança nos conceitos compartilhados sobre gênero, como que se estivesse preparando-a para dar futuras respostas para as perguntas que a sociedade fará diante de certos comportamentos. Para Kishimoto e Ono (2008) as crianças manifestam suas experiências e vivências no âmbito familiar e escolar, os autores ainda argumentam que os estereótipos são oriundos dos pais e de pessoas próximas da criança, e os pais são aqueles que impõem os primeiros padrões antes que ela comece a fazer suas próprias escolhas. Durante uma gestação já é imposto de que se o bebê for uma menina o quarto deverá ser rosa e cheio de bonecas, mas se for um menino o quarto tem que ser azul com inúmeros carros em miniatura. Portanto, é evidente que o contexto em que a criança vive interfere e direciona suas escolhas.

Os adultos apresentam certo estranhamento quando meninas brincam com os meninos e gostam de jogar futebol, e quando meninos brincam com meninas e gostam de bonecas (FINCO, 2013). Cada cultura irá definir o que é feminino e masculino e quais suas implicações, mas isso não deve se tornar algo imutável, estas definições devem sofrer modificações conforme a sociedade muda. Algumas designações culturais, feminino e masculino, estão presentes no dia a dia das crianças e as influenciam, por exemplo, afirmar que homem não chora não significa que ele não é fisiologicamente capaz de chorar, mas que tal comportamento não faz jus ao seu gênero (VIANNA e RIDENTI, 1998). Compreende-se que a sociedade estabelece um tipo de treinamento social, onde as meninas são ensinadas a serem dóceis, sensiveis, frágeis e capacitadas para cuidar dos filhos. Já os meninos são ensinados a serem fortes, bravos, aventureiros e totalmente alheios à vida familiar, sendo constantemente monitorados quanto à construção de suas masculinidades.

Ao tratar deste assunto é imprescindivel atuar sobre o ambiente escolar, que como já foi citado antes é um dos ambientes de socialização e construção dos sujeitos. Na escola o indivíduo irá construir sua identidade. Sobre isso Silva (2000, p. 97) diz que:

A questão da identidade, da diferença e do outro é um problema social ao mesmo tempo em que é um problema pedagógico e curricular. É um problema social porque, em um mundo heterogêneo, o encontro com o outro, com o estranho, com o diferente, é inevitável. É um problema pedagógico e curricular não apenas porque as crianças e os jovens, em uma sociedade atravessada pela diferença, forçosamente interagem com o outro no próprio espaço da escola, mas também porque a questão do outro e da diferença não pode deixar de ser matéria de preocupação 
pedagógica e curricular.

Sabe-se que no âmbito escolar o tema gênero não faz parte do currículo e nem da formação docente, por isso muitas vezes o conceito de gênero é relacionado ao masculino e feminino, ou apenas relacionado ao sexo e sexualidade. $A$ rotina escolar das crianças é repleta de interações, sejam por meio de diálogos, da literatura, dos brinquedos, brincadeiras e é assim que se (re)significa e se caracteriza questões relacionadas a gênero (CARPES, 2016). A escola precisa se reinventar, Araújo e Barbosa (2016, p. 57) afirmam que temos que combater a escola "segregadora, excludente, meritocrática, elitista e reprodutora de sujeitos acríticos e modelados por uma estrutura normalizadora e normatizadora que, acima de tudo, reforça situações de abjeção e de alienação".

A importância da discussão sobre assuntos relacionados a gênero está associada à forma como os padrões culturalmente estabelecidos influenciam na vida das pessoas, indicando a construção de identidades que iniciam logo na infância. Entendendo a escola como um grande centro de trocas sociais provenientes da constante interação dos alunos, professores e comunidade, se torna evidente a importância de abordar este tema, problematizando, discutindo e instigando o respeito pelo outro, promovendo assim a igualdade de gênero na infância e para toda a vida.

\section{Metodologia}

O presente trabalho foi desenvolvido em uma escola pública de ensino fundamental do município de Canoas, RS. Foram realizadas cinco atividades nos meses de outubro e novembro do ano de 2016, com duas turmas da Educação Infantil, uma turma do $2^{\circ}$ ano composta por 17 alunos e outra do $3^{\circ}$ ano composta por 13 alunos, totalizando 30 alunos com faixa etária de 6 a 10 anos.

\section{Atividade 1: Questionário}

Na primeira atividade foi aplicado um questionário (figura 1), que continha perguntas como Qual sua cor preferida? e Quais brinquedos você gosta? Como os alunos ainda não sabiam escrever e ler muito bem, os bolsistas explicaram as perguntas e na folha do questionário havia cores e objetos para assinalarem. $\mathrm{Na}$ última pergunta referente às brincadeiras, como opção para marcar havia quatro imagens: uma de dois meninos jogando vídeo game, um menino brincando com carrinhos e bonecos, outra de uma menina brincando de pular amarelinha e a última era de uma menina jogando futebol. 
Figura 1: Questionário

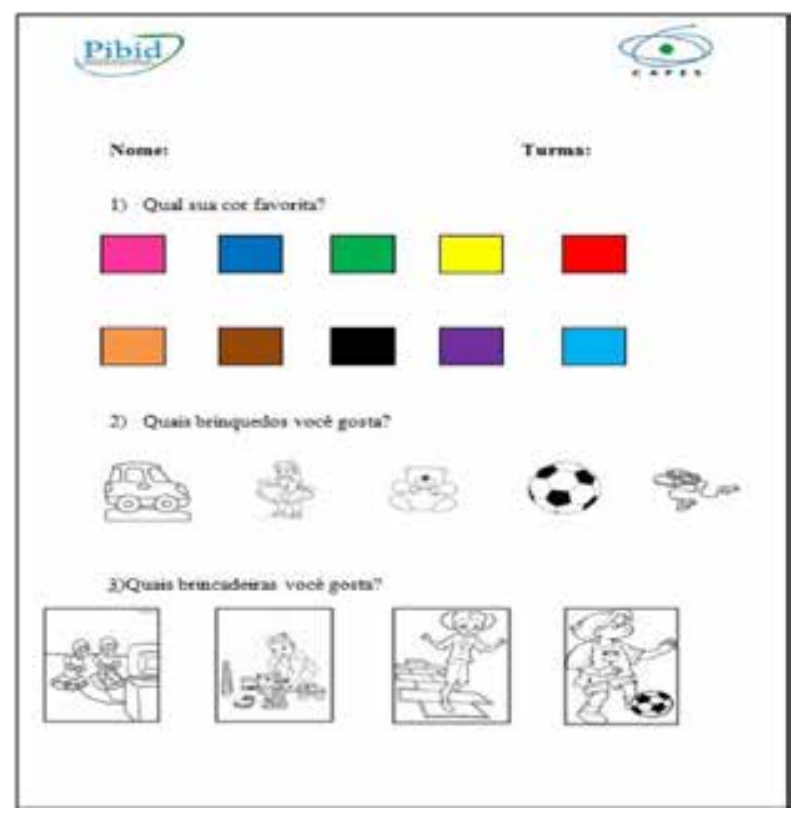

Fonte: Elaborado pelos autores (2016).

\section{Atividade 2: Teatro de Fantoches Tudo é de Menino e de Menina}

Na segunda etapa foi realizado o teatro de fantoches, onde os bolsistas levaram os alunos para a sala em que o cenário foi montado. A peça conta a história de dois amigos, Andrezinho e Aninha. A peça tem cinco cenas e cada uma delas aborda temas referentes a gênero. Na primeira cena o tema abordado são as brincadeiras, onde Aninha diz para Andrezinho que adora jogar futebol e que quer ser jogadora profissional quando crescer.

$\mathrm{Na}$ cena seguinte as crianças se sentam para conversar e Aninha pergunta para Andrezinho qual sua cor favorita, ele diz que é a cor rosa. Aninha também lhe pergunta o que ele quer ser quando crescer, e ele diz: quero dançar, eu amo dançar! Sonho em participar de uma companhia de dança para percorrer o mundo realizando apresentações.

$\mathrm{Na}$ cena três os dois amigos brincam com o carrinho que Andrezinho trouxe e Aninha quase o quebra, chateado com a amiga, Andrezinho pede para ela ser mais delicada, ao ouvir isso Aninha responde: Desculpe Andrezinho! É que eu não sou delicada não, gosto de correr e brincar de uma maneira mais agitada mesmo. Sempre quebro os meus brinquedos e gosto de desmontar eles e montar tudo de novo! Assim eu faço de conta que sou uma mecânica especializada em brinquedos (risos). Mas prometo ser mais cuidadosa com os seus brinquedos! Andrezinho diz 
entender o jeito agitado de Aninha.

$\mathrm{Na}$ última cena da peça, já está na hora dos amigos irem para suas casas. Aninha diz para seu amigo que quer jogar futebol com ele um dia desses, se despede e sai andando em direção a sua mãe. Ao ver Andrezinho sozinho ela pergunta: Mas você vai ficar aí sozinho esperando sua mãe e seu pai. $O$ amigo responde: Não Aninha. Eu não tenho mãe, eu tenho dois pais, logo um deles vem me buscar. Aninha se despede e assim se encerra o teatro.

\section{Atividade 3: Roda de conversa}

Após o teatro, os bolsistas pediram para que os alunos se sentassem em círculo e conversassem sobre a peça, pois este era o momento em que podiam relatar suas opiniões de uma forma dinâmica e espontânea. Os bolsistas também levantaram algumas questões que se destacaram durante a peça, como o que os alunos pensavam sobre meninos brincarem de brincadeiras consideradas de menina, $\circ$ que achavam das cores rosa e azul e o que pensavam sobre meninas brincando de carrinho. Essas questões foram expostas para que os alunos expressassem suas opiniões e compartilhassem suas vivências.

\section{Atividade 4: Vídeos}

No segundo dia de atividades, os bolsistas levaram os alunos para a sala de multimídia onde foram exibidos os vídeos: Ferdinando o touro, Matteo - Coisas de menina e de menino e o clipe da banda Hollysiz com a música The light. Logo abaixo segue uma breve sinopse dos vídeos escolhidos e o porquê desta escolha. Ferdinando o touro: Ferdinando desde pequeno era um touro calmo e tranquilo, não gostava de brigar e adorava o perfume das flores, gostava de se sentar debaixo das árvores e relaxar. Ele cresceu e se tornou um touro grande e forte, mas continuava do mesmo jeito, calmo e tranquilo. Até que um dia cinco homens foram até sua fazenda escolher um touro para participar de touradas, e Ferdinando foi o escolhido. Chegando às touradas Ferdinando não quis lutar, quis apenas cheirar as flores que estavam na arena, o que gerou espanto e confusão da plateia e dos toureiros, que não entendiam como um touro pudesse gostar tanto de cheirar flores ao invés de guerrilhar na arena. Esse vídeo foi escolhido justamente por apresentar uma situação que aborda as diferenças e preconceitos, pois mesmo os touros sendo caracterizados como brabos e briguentos, Ferdinando era diferente e isso não era bem aceito pela população.

Matteo - Coisas de menina e de menino: Matteo Brandão Procópio tem 8 anos e neste vídeo resolveu falar sobre coisas de menina e de menino. Ele relata no vídeo que essa classificação não tem que existir, as crianças podem brincar com qualquer brinquedo independente de ser menino ou menina. Ele fala sobre 
brinquedos, o preconceito referente aos meninos brincarem de boneca e sobre as cores das roupas, também relata que cada um tem o seu jeito e isso tem que ser respeitado. Esse vídeo foi escolhido principalmente pela mensagem que $\circ$ Matteo passa e também por ele ser uma criança. Matteo apresenta uma pureza e mostra que é preciso respeitar as diferenças, e que não há problema em uma menina jogar bola e um menino brincar de boneca.

Banda Hollysiz - The light: $\bigcirc$ mais interessante desta música é o clipe, que mostra a história de um menino que gosta de usar um vestido lilás. Quando ele vai para a escola usando o vestido os colegas debocham da sua maneira de se vestir, o menino acaba ficando isolado e sem amigos. Sua mãe é a única pessoa que o apoia e aceita sua forma de ser, o pai se mostra muito indignado com a situação e age de forma ríspida e grosseira com o filho. Após ter imposto um castigo ao menino por estar usando o vestido lilás, o pai se sente frustrado e reflete sobre a situação arrependendo-se do ocorrido. O clipe termina com ele indo buscar o filho na escola usando um vestido. $O$ clipe trás uma problemática muito importante, abordando as questões de gênero e bullying no meio familiar e escolar.

\section{Atividade 5: Desenhos}

Após os vídeos, cada aluno foi orientado a desenhar livremente aquilo que mais havia chamado sua atenção nos assuntos discutidos.

\section{Resultados e Discussões}

Para análise dos questionários salienta-se que os alunos puderam optar por mais de uma opção para resposta. Primeiramente foram analisados os dados dos alunos da turma do $2^{\circ}$ ano. Ao observar o questionário constatou-se que na primeira pergunta Qual a sua cor favorita? as cores mais citadas pelas meninas foram azul (37\%), vermelho (25\%) e roxo (25\%). Nenhuma aluna citou a cor rosa, que pelo senso comum é considerada cor de menina. As cores mais citadas pelos meninos foram a preto (33\%), vermelho (33\%) e azul (44\%). A cor mais citada pelos meninos foi a azul, mas a cor rosa também foi comentada.

Posteriormente, foram analisados os dados dos questionários dos alunos do $3^{\circ}$ ano e referente à primeira pergunta Qual a sua cor favorita? a cor mais citada pelos meninos foi a azul (66\%), em segundo a cor vermelha (44\%), apenas um aluno marcou a cor rosa, ele relatou adorar todas as cores. Entre as meninas $50 \%$ optaram pela cor roxa, sendo esta a mais citada por elas. As meninas relataram gostar das cores azul, rosa, vermelho, roxo e amarelo.

Segundo Carpes (2016) a identidade de gênero começa a ser formada muito antes do nascimento da criança, e ocorre quando os pais descobrem o sexo do 
bebê, a partir deste momento a vida deste indivíduo começa a ser traçada pelas cores que ele usará ao nascer. $O$ enxoval é iniciado e se for menina deve conter peças de roupas da cor rosa e o quarto também será, provavelmente, da mesma cor. Já os meninos terão que usar roupas azuis e ter um quarto azul, mas o leque de cores consideradas masculinas é expressivamente maior do que as consideradas femininas. Pesquisas realizadas sobre cores socialmente recomendadas para meninos apontam que as cores azul, cinza, laranja, preto, amarelo e vermelho, são cores pertencentes ao gênero masculino (KELLER e ARAÚJO, 2015). Para as meninas é recomendado o uso da cor rosa e lilás, o aparecimento da cor azul em suas vestimentas só deverá ser aplicado em vestidos e blusas, acompanhados por uma estampa com elementos femininos como laços, corações e sapatos (CARPES, 2016). Os tons de cores vivas são usados em peças publicitárias voltadas para crianças do gênero masculino, pois estimula a ação, aventura e estão associadas com o masculino. As cores mais suaves e claras, ditas femininas estão associadas à fragilidade e delicadeza das meninas.

Além das cores que segregam o que seriam roupas femininas e masculinas, as peças femininas encontradas em praticamente qualquer loja, geralmente apresentam o mesmo padrão, compostas por figuras de princesas, bichinhos, ou escritas que enfatizam a beleza. Já as roupas infantis para os meninos apresentam frases de motivação, imagens de carros, skates, naves espaciais e com um enfoque aventureiro. Evidenciando de que meninas precisam ser delicadas e bonitas, enquanto os meninos podem ser rebeldes, aventureiros e exploradores. Para elucidar melhor tais argumentos, seguem imagens de vestimentas encontradas em lojas de todo o país.

Figura 2: Roupas infantis femininas e masculinas
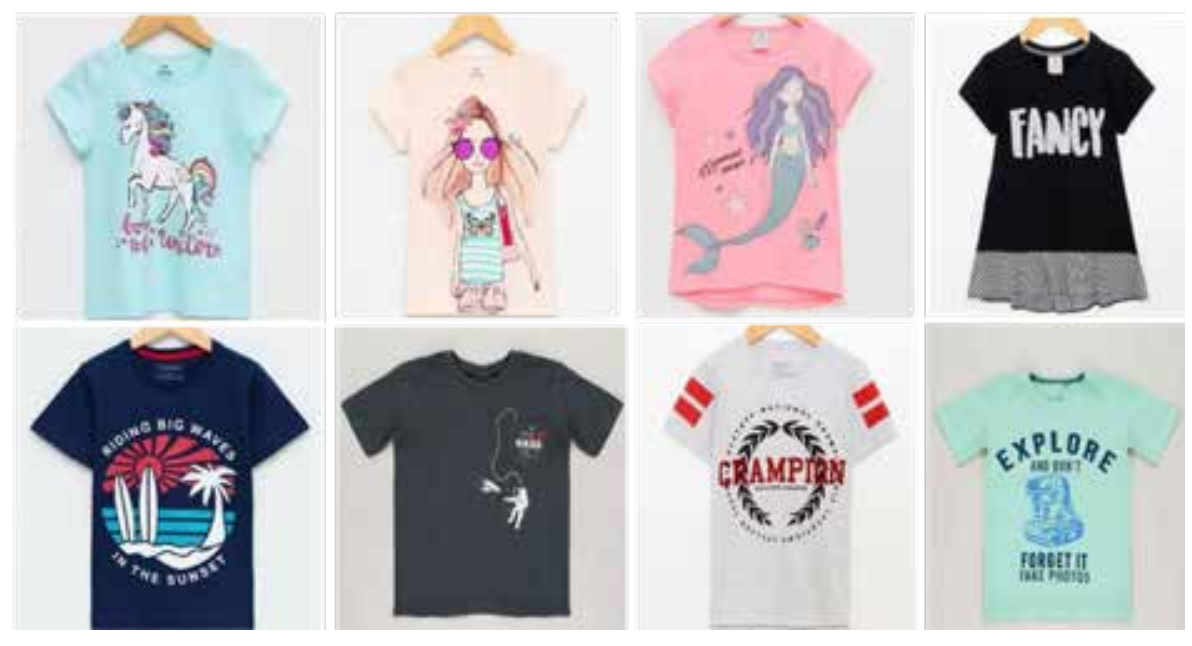

Fonte: Google imagens (2018). https://www.google.com/imghp?hl=pt-BR 
Referente à segunda pergunta do questionário Quais brinquedos você gosta? $\mathrm{Na}$ turma do $2^{\circ}$ ano o brinquedo mais apontado pelas meninas foi a boneca $(75 \%)$, seguido por vídeo game (50\%). A sociedade impõe para as meninas que jogar vídeo game é uma brincadeira masculina, mas é perceptivel que muitas gostam e algumas delas relataram que brinquedo não tem gênero. Os brinquedos mais citados pelos meninos foram vídeo game (77\%), bola (55\%) e carrinho (55\%), mas ursinhos de pelúcia também foram citados por eles. Alguns alunos ainda aparentam ter certo receio em brincar de boneca, mas muitos disseram gostar e ter ursinhos de pelúcia, que é um brinquedo também considerado de menina.

$\mathrm{Na}$ pergunta sobre os brinquedos, as meninas da turma do $3^{\circ}$ ano escolheram o urso (50\%) e a boneca (50\%), mas relataram gostar de bola e vídeo game, também comentaram que meninas podem brincar daquilo que quiserem. Os meninos optaram pelo vídeo game (100\%), a bola (100\%) e o carrinho (22\%), relataram que não estão acostumados a brincar com outros brinquedos e afirmaram que boneca é coisa de menina.

Os brinquedos se tornaram elementos culturais e que socialmente constituem o sentido da infância e do que é ser criança (LIRA e NUNES, 2016). Para Campos e de Queiroz Silva (2015, p. 216), os brinquedos atuam como "instâncias que colocam em funcionamento a pedagogia da fabricação de homens e mulheres". É um objeto que está carregado de cultura e significados posto ao alcance das crianças, se tornando seu parceiro diário e possibilitando a criança ações como agir e imaginar (KISHIMOTO, 1999). Já Vygotsky (1994, p. 135) afirma que "o brinquedo não é o aspecto predominante da infância, porém é um fator importante no seu desenvolvimento", os brinquedos acabam criando uma espécie de zona no desenvolvimento da criança, porque ele faz com que ela se porte de maneira diferente dos comportamentos habituais de sua idade. Um exemplo é quando meninas brincam de boneca, elas praticamente imitam os comportamentos de suas mães, sendo assim o brinquedo não estaria associado diretamente com a imaginação e sim com uma lembrança do que aconteceu (CARPES, 2016). "É mais a memória em ação do que uma situação imaginária nova" (VYGOTSKY, 1994, p. 135). Assim é importante analisar a relação entre bonecas e meninas, como também os utensilios domésticos que acompanham as bonecas simbolizando que as meninas devem se ocupar apenas com as tarefas domésticas.

Com os brinquedos masculinos também há significações que impõem maneiras de agir, a maioria dos bonecos são musculosos acompanhados de instrumentos de luta. Os anúncios publicitários destinados aos meninos reúnem brinquedos onde o foco principal é a aventura, nestes os garotos são os protagonistas e estão preparados para enfrentar todos os perigos com muita força e coragem. Outro fato interessante é que os brinquedos para os meninos possuem grande possibilidade de transformação, o produto permite e estimula a montagem e remontagem, incentivando o pensamento lógico e despertando a curiosidade (ALCÂNTARA e GUEDES, 2014). 
Os meninos são mais suscetiveis a serem atraídos por brinquedos que enfatizem, na sua percepção, a força e a coragem, pois a masculinidade é definida por tais características. Um estudo relatado por Fine (2012) analisou as diferentes reações das crianças ao brinquedo meu pequeno pônei, este possui cores em tom pastel e apresenta traços suaves tidos como femininos. $O$ brinquedo foi colorido com a cor preta e nele foram acrescentados dentes pontiagudos representando agressividade. Ao observar a transformação do brinquedo, tanto os meninos quanto as meninas classificaram o brinquedo como sendo de menino.

Percebe-se que esses objetos são impregnados de significações sobre como ser homem e mulher, e é nesses objetos industrializados que as crianças aprendem modos de ser menina e menino (LIRA e NUNES, 2016).

Quanto à terceira pergunta do questionário Quais brincadeiras você gosta? a brincadeira mais citada pelas meninas do segundo ano foi amarelinha (75\%), e a segunda brincadeira mais comentada foi jogar vídeo game (62\%). Mais uma vez percebe-se que as meninas cada vez mais estão desconstruindo estereótipos estabelecidos socialmente. A brincadeira preferida dos meninos foi jogar vídeo game (88\%) e em segundo jogar futebol (77\%), mas a amarelinha foi muito comentada pelos meninos, pois $44 \%$ escolheram essa opção como brincadeira preferida. No terceiro ano $75 \%$ das meninas escolheram amarelinha, apenas uma menina escolheu jogar futebol. Os meninos escolheram jogar vídeo game (100\%) e jogar futebol (100\%), nenhum deles optou por brincar de boneca ou de amarelinha, argumentaram que essas brincadeiras são de menina. Geralmente as brincadeiras agressivas e que fazem o indivíduo correr riscos são para meninos, já brincadeiras que tenham alguma fragilidade e delicadeza são para as meninas. Se um menino resolve durante a brincadeira fazer um bolo será chamado pelos colegas de mulherzinha, portanto, as brincadeiras também moldam as crianças thes impondo padrões considerados corretos. Conforme Nunes (2016) é na infância que se inicia a desigualdade de gênero, pois se aprende que meninas gostam de brincar de afazeres domésticos e os meninos gostam de futebol. A autora ainda conclui que:

As diferenças entre meninas e meninos são justificadas como naturalidade do gênero e não existe uma intencionalidade de conceder tanto as meninas quanto aos meninos as mesmas chances de ingresso às várias proporções da cultura infantil. Sabemos que as meninas não são encorajadas a jogar futebol. Os professores defendem os meninos usando a expressão "fominhas por bolas"; e justificam essas escolhas afirmando que as meninas optam por assistir ao jogo; pois elas desconhecem as regras do futebol, podendo se machucar e desse modo desistem de jogar. (NUNES, 2016, p. 20).

$\mathrm{Na}$ roda de conversa com os alunos do $2^{\circ}$ ano houveram debates interessan- 
tes. Alunos relataram que cores e brinquedos não possuem gênero, disseram que as pessoas são livres para fazer o que quiserem e se mostraram chateados com a sociedade, pois as pessoas desaprenderam a respeitar o próximo. Apenas $11 \%$ dos alunos apresentaram falas preconceituosas, relataram que não compreendem porque um menino iria usar vestido se este é uma roupa de menina. No segundo dia de atividades, após assistirem o vídeo e irem realizar os desenhos, as falas preconceituosas desapareceram e todos os alunos relataram que é necessário aprender a respeitar o outro. Nos desenhos pintaram o touro Ferdinando com flores ao seu redor e afirmaram que o touro só queria ser ele mesmo (figura 3 e 4). Verifica-se então que os alunos conseguiram derrubar estereótipos estabelecidos e aprenderam a aceitar e respeitar o próximo.

Figuras 3 e 4 : Desenhos do Touro Ferdinando dos alunos do $2^{\circ}$ ano

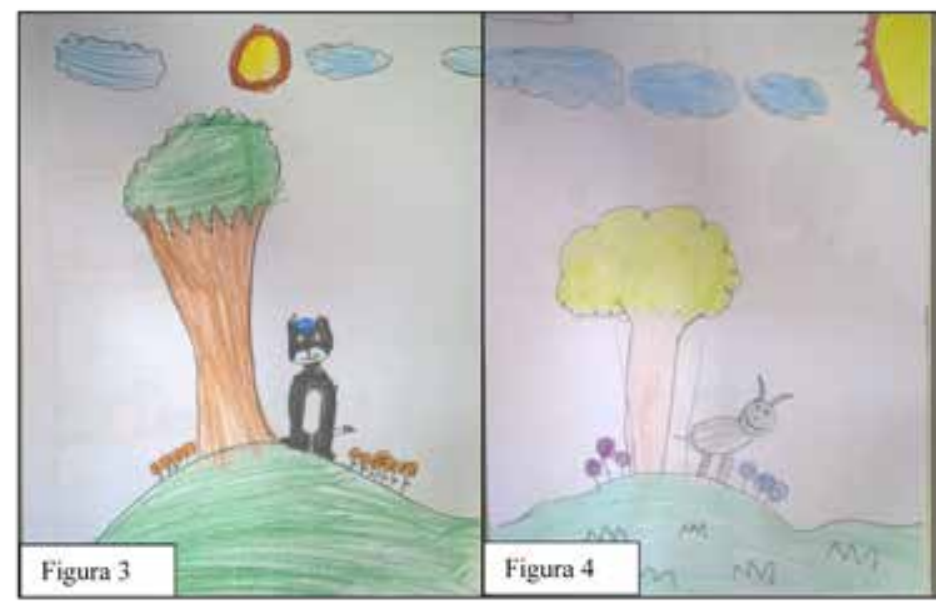

Fonte: Elaborada pelos Autores (2016)

$\mathrm{Na}$ roda de conversa os alunos do $3^{\circ}$ ano afirmaram que existem brinquedos de menina e de menino, mas quando questionados o porquê disso eles não souberam responder. Ao longo da conversa foram mudando de opinião e afirmavam que não deveriam existir brinquedos de menina ou de menino. No segundo dia de atividades após os alunos assistirem os vídeos, os discursos mudaram. Uma aluna disse: Esses vídeos são importantes para a nossa sociedade, todos tinham que assistir para aprender a respeitar o próximo. Afirmaram que é preciso respeitar a opinião do outro, pois não podem interferir na vida do próximo e nem rir dos colegas. Nos desenhos dos alunos o vídeo mais representado foi o da música The Light, os alunos desenharam o pai e o menino usando vestidos floridos (figura 5 e 6). Ao comparar 
a primeira aula e a última é perceptível uma mudança de opinião e comportamento, aqueles que reproduziam falas preconceituosas mudaram seu discurso e afirmaram que é necessário aprender a respeitar as diferenças.

Figuras 5 e 6 : Desenhos do clipe da música The Light dos alunos do $3^{\circ}$ ano

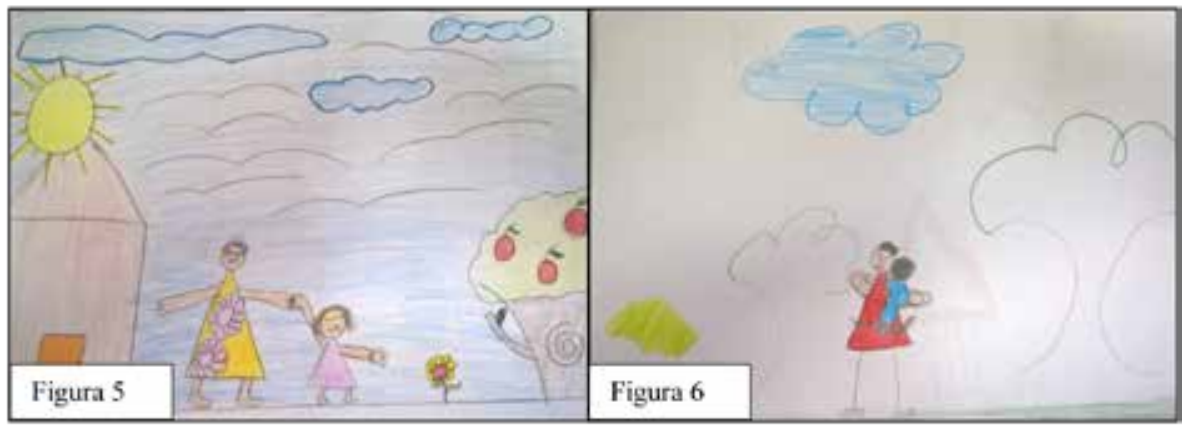

Fonte: Elaborada pelos Autores (2016).

$\mathrm{Na}$ roda de conversa os alunos do $3^{\circ}$ ano afirmaram que existem brinquedos de menina e de menino, mas quando questionados o porquê disso eles não souberam responder. Ao longo da conversa foram mudando de opinião e afirmavam que não deveriam existir brinquedos de menina ou de menino. No segundo dia de atividades após os alunos assistirem os vídeos, os discursos mudaram. Uma aluna disse: Esses vídeos são importantes para a nossa sociedade, todos tinham que assistir para aprender a respeitar o próximo. Afirmaram que é preciso respeitar a opinião do outro, pois não podem interferir na vida do próximo e nem rir dos colegas. Nos desenhos dos alunos o vídeo mais representado foi o da música The Light, os alunos desenharam o pai e o menino usando vestidos floridos (figura 5 e 6). Ao comparar a primeira aula e a última é perceptivel uma mudança de opinião e comportamento, aqueles que reproduziam falas preconceituosas mudaram seu discurso e afirmaram que é necessário aprender a respeitar as diferenças.

Os padrões culturais que envolvem gênero estão inseridos diariamente na vida de todos os indivíduos, são expressos nos hábitos, preferências, ideais e escoIhas, moldam desde a infância o modo de entender-se e entender o outro. Para Louro (1999, p. 77) gênero refere-se "ao modo como as diferenças sexuais são compreendidas numa dada sociedade, num determinado grupo, em determinado contexto". As ações consideradas de menino e de menina, de homem e mulher, são engendradas no contexto cultural e interpelam os indivíduos a adotarem uma postura criada culturalmente. Conforme é preconizado para os anos iniciais pelos Parâmetros Curriculares Nacionais (PCN): 
A postura do educador é fundamental para que os valores básicos propostos possam ser conhecidos e legitimados de acordo com os objetivos apontados. Em relação às questões de gênero, por exemplo, o professor deve transmitir, pela sua conduta, a equidade entre os gêneros e a dignidade de cada um individualmente. Ao orientar todas as discussões, deve, ele próprio, respeitar a opinião de cada aluno e ao mesmo tempo garantir o respeito e a participação de todos (BRASIL, 1998, p. 84).

De acordo com Angrosino (2009, p. 16) "o modo de vida peculiar que caracteriza um grupo é entendido como a sua cultura. Estudar a cultura envolve um exame dos comportamentos, costumes e crenças aprendidos e compartilhados do grupo". É nessa construção cultural de identidades que se torna evidente a importância de práticas que visam relacionar e problematizar assuntos relacionados a gênero dentro da escola.

\section{Considerações Finais}

A abordagem sobre gênero na infância propiciou um momento de releitura dos padrões estabelecidos socialmente. Nenhuma menina citou a cor rosa como cor favorita. A cor mais citada pelos meninos foi azul, mas rosa também foi comentada durante a aula. Ficou claro que as meninas gostam de jogar vídeo game e que alguns meninos possuem certo receio em brincar de boneca, porém alguns disseram gostar e ter ursinhos de pelúcia. Diante da empolgação dos alunos após o teatro de bonecos e da exibição dos vídeos, percebe-se que práticas diferenciadas são fundamentais no processo de ensino-aprendizagem, propiciando a abordagem de assuntos relacionados a gênero de forma interessante e natural tal como deve ser.

A sociedade atual ainda segue modelos de comportamentos para homens e mulheres, o que leva a discriminação para ações que não estejam dentro destes padrões, gerando intolerância e preconceito. Infelizmente a escola acaba operando essas regras e normas de comportamentos que são entendidas como apropriadas para cada um dos gêneros. As crianças, como grandes observadoras do mundo adulto, podem reproduzir o que escutam em casa na escola, ou vice-versa, neste trabalho elas foram capazes de chegar as suas próprias conclusões. Foi perceptivel que embora repercutam o discurso adulto, não sabem o significado do mesmo ou o porquê dele. Muitos alunos iniciaram a atividade com um pensamento, mas após debater com os colegas eles acabaram reelaborando suas opiniões. As crianças de certa forma captam informações das culturas escolares, dos adultos e dos colegas para gerar sua própria cultura e identidade perante a sociedade, por isso é tão importante que atividades do tema gênero sejam aplicadas em sala de aula. A escola tem gênero, sexo e classe social, então deve ser a instituição onde todos possam ser acolhidos e possibilitar o despertar do conhecimento de um novo mundo, sem 
preconceitos e com liberdade.

\section{Referências}

ALCÂNTARA, A., GUEDES, B. Culturas infantis do consumo: práticas e experiências contemporâneas. São Paulo: Pimenta Cultural, 2014.

ANGROSINO, M. Etnografiae observação participante. Porto Alegre: Artmed, 2009.

ARAÚJO, Eduardo Oliveira Henriques de; BARBOSA, Guilherme. As performatividades de gênero no espaço escolar: abjeção e formação crítica para a cidadania. Cadernos de Estudos e Pesquisa na Educação Básica, v.2, n.1, 2016, p. 51-72.

BRASIL. Ministério da Educação. Secretaria de Educação Fundamental. Parâmetros Curriculares Nacionais: $1^{\mathrm{a}}$ a $4^{\mathrm{a}}$ Séries. Brasilia: MEC/SEF, 1998.

CAMPOS, Patrícia Lemos; QUEIROZ SILVA, Elenita Pinheiro de. Modos de ensinar e aprender a ser menina e a ser menino. Revista de Educação PUC-Campinas, v.19, n.3, p. 215-225, 2015.

CARPES, H. Gênero na Educação Infantil. 2016. Monografia - Universidade Federal de Santa Catarina, Florianópolis. 2016.

CORSARO, W. Reprodução interpretativa e cultura de pares. In: MÜLLER, F., e CARVALHO, A. (Orgs.). Teoria e prática na pesquisa com crianças: diálogos com William Corsaro. São Paulo: Cortez Editora. 2009. p. 31-50.

EUGENIO, Benedito. No interior da sala de aula: as relações de gênero nos anos iniciais do ensino fundamental. Interfaces Científicas - Educação, Aracajú, v. 4, $n^{\circ} 3$, Jun 2016. p. $139-150$.

FINCO, Daniela. Os perigos da naturalização das relações sociais na educação infantil. Revista Pátio: educação infantil.Porto Alegre, 2013, p. 05-07.

FINE, C. Homens não são de marte, mulheres não são de Vênus. São Paulo: Cultrix, 2012.

FURLANI, J. O bicho vai pegar! - um olhar pós-estruturalista à educação sexual a partir de livros paradidáticos infantis. 2005. Tese (Doutorado em Educação) Universidade Federal do Rio Grande do Sul, Porto Alegre. 2005.

KELLER, Daniel; ARAÚJO, Denise Castilhos de. Azul ou rosa: manifestações identitárias de gênero sob o viés normativo do consumo. PerCursos, v. 16, n. 30, 2015, p. 221-235. 
KISHIMOTO, T. M. Jogo, brinquedo, brincadeira e educação. São Paulo: Cortez, 1999.

; ONO, Andréia Tiemi. Brinquedo, gênero e educação na brinquedoteca. Campinas: Proposições, v.19, n.3, 2008, p.209-223.

LIRA, Aliandra Cristina Mesomo; NUNES, Maristela Aparecida. Ensinando a ser menina e menino: Brinquedos e relações de gênero. Revista Ensino \& Pesquisa, v. $14 ;$ n. $01 ; 2016$.

LOURO, G. L. Gênero, sexualidade e educação: uma perspectiva pós - estruturalista. Petrópolis: Vozes, 1999.

MARTINS, Cícero Félix. Gênero e Sexualidade na Educação Contemporânea. Id onLine Revista de Psicologia, v.10, n.33, 2017, p.257-270.

MEYER, Dagmar Estermann. Gênero e educação: teoria e política. Corpo, gênero e sexualidade: um debate contemporâneo na educação, v. 2, 2003, p. 9-27.

NOVAKOWSKI, Lutiane; COSTA, Marisa Vorraber; MARCELLO, Fabiana de Amorim. Representações de feminino e masculino em pesquisa com crianças. Revista Zero-a-seis, v. 18, n. 34, 2016, p. 235-248.

NUNES, Eugenia Lucia dos Santos. Gênero e sexualidade na educação infantil:um estudo sobre a construção e a reprodução de "ser menino" e "ser menina". 2016. Trabalho de Conclusão de Curso (Graduação em Pedagogia) - Universidade Estadual da Paraíba, Campina Grande, 2016.

SILVA, Tomaz Tadeu. A produção social da identidade e da diferença. Identidade e diferença: a perspectiva dos estudos culturais.Petrópolis, RJ: Vozes, 2000. p. 73-102.

VIANNA, Claúdia; RIDENTI, Sandra. Relações de gênero e escola: das diferenças ao preconceito. In: AQUINO, Julia Groppa. Diferenças e preconceito na escola: alternativas teóricas e práticas. São Paulo: Summus, 1998.

VYGOSTSKY, L. S. A Formação Social da Mente. 5. ed. São Paulo: Martins Fontes, 1994.

Recebido em dezembro de 2018.

Aprovado em março de 2019. 